Personalidade Acadêmica Homenageada:

Carlos Aurélio Mota de Souza (Universidade Ibirapuera - UNIB)

\title{
O MAL POLÍTICO COMO DESAFIO AO ESTADO CONTEMPORÂNEO: RACIONALIDADE JURÍDICA COMO RESISTÊNCIA ANTI-AUTORITÁRIA
}

\section{THE POLITICAL EVIL AS A CHALLENGE TO THE CONTEMPORARY STATE: LEGAL RATIONALITY AS ANTI-AUTHORITY RESISTANCE}

\section{ELISEU RAPHAEL VENTURI}

Doutorando em Direitos Humanos e Democracia pela Universidade Federal do Paraná (2015-2019). Mestre em Direitos Humanos e Democracia pela Universidade Federal do Paraná (2012-2014). Especialista em Direito Público pela Escola da Magistratura Federal no Paraná (2012). Graduado em Direito pelo Centro Universitário Curitiba (2010). Membro do Comitê de Ética em Pesquisa com Seres Humanos da Universidade Federal do Paraná. Advogado. eliseurventuri@gmail.com

\section{RESUMO}

O tema deste resumo expandido é o do mal ou horror político, concretizado em sistemas político-jurídicos de feições autoritárias ou totalitárias. A delimitação do tema se dá no debate do tema a partir da noção de banalidade do mal, assim como de resistência anti-autoritária (democrática), entendidos, então, enquanto desafios tanto dos fundamentos do Direito quanto também do Estado contemporâneo.

O objetivo geral da pesquisa é o de discutir dimensões éticas constantes do direito contemporâneo e suas construções pós Segunda Guerra Mundial em torno à interdição do horror e do mal políticos, cujas desumanidades foram decorrentes de sistemas políticos e jurídicos absenteístas de juízos de valor, compromissos éticos, 


\section{Personalidade Acadêmica Homenageada:}

\section{Carlos Aurélio Mota de Souza (Universidade Ibirapuera - UNIB)}

proteção e promoção de direitos humanos e violações de prerrogativas democráticas.

Como objetivos específicos adotam-se: a. identificar o cenário de valoração e compreensão éticos do mal ou horror político, sobretudo no tocante aos sistemas político-jurídicos de feição autoritária ou totalizante, ou em cujas democracias precárias se identifiquem tais infiltrações; b. elaborar, no contexto do pensamento jurídico e da teoria política estatal, a crítica às práticas anti-democráticas; c. estabelecer o conjunto de possíveis resistências ínsitas às formas jurídicas de interpretação e de valoração a partir do estado da arte da Filosofia Contemporânea do Direito.

O problema da pesquisa se estrutura sobre quais os lapsos de racionalidade se podem identificar no mal ou horror político e quais suas relações com os compromissos e valores democráticos, especialmente na demanda de resistências legítimas?

A hipótese central é a de que a banalidade do mal pode se instaurar em diversos espaços de liberdades e direitos democráticos, institucionais ou não, por meio de ações de autoridade ou cidadãos, e que esta banalidade institui fissuras e fraturas de racionalidade que fomentam o desenvolvimento de práticas, crenças, concepções e valorações de cunho autoritário e totalizante. A violação da cultura da democracia e a interdição da efetividade de direitos fundamentais e humanos, institui arbitrariedades, violências e normalizações deletérias à democracia, em cujos meandros transmuta-se o sistema de modo ilegítimo e contraditório.

A justificativa do estudo se consolida em razão das novas feições da compreensão do Direito estabelecidas na Filosofia Contemporânea do Direito com o pós-positivismo dos anos 1960, impondo-se novas dimensões ao fenômeno jurídico, incluindo aspectos axiológicos, institucionais, do raciocínio jurídico e dos novos desafios tecnológicos ao Direito. Soma-se a isto a refundação dos direitos humanos pós Segunda Guerra em torno às interdições dos fenômenos totalitários e de conflito e seus resultados desastrosos em termos humanos, sociais e ambientais. 
Personalidade Acadêmica Homenageada:

Carlos Aurélio Mota de Souza (Universidade Ibirapuera - UNIB)

Como marco teórico adotam-se aportes: 1 . Sobre o mal ou horror político; 2. Sobre a racionalidade jurídica como postura de resistência anti-autoritária e de afirmação das liberdades e valores da democracia.

Sobre o horror político, centra-se a discussão em torno à "banalidade do mal", noção filosófica estabelecida por Hannah Arendt $(1989,1990)$ enquanto referencial analítico da perpetração de crimes contra a humanidade sem a oposição da resistência que se esperaria. Pela banalidade do mal, compreende-se que o horror político não se apresenta como fenômeno isolado ou extraordinário, mas, antes, por sua presença constante, demanda a vigilância do pensamento e da reflexão como modo de elaboração desta conduta social (ANDRADE, 2010) (BOTERO; LEAL GRANOBLES, 2013).

A Filosofia Contemporânea do Direito, veiculando ciência desta necessidade de vigilância (BILLIER, 2016) (FARALLI, 2006) (MORRISON, 2006), teve nos desenvolvimentos de suas discussões debates avançados sobre a abertura do Direito aos valores, aos fatos, à necessidade da conformação democrática das instituições e da construção dos direitos humanos como referencial de normatividade e valoração. A alteridade, inclusive, ao afirmar a ética como filosofia primeira (LÉVINAS, 2010), assim como a ética da comunicação demandando racionalidade na esfera pública da convivência coletiva (HABERMAS, 2003, 2004) influenciaram profundamente as técnicas jurídicas, falando-se, inclusive, em humanização do direito (TRINDADE, 2006) e relacionando-se profundamente humanismo e democracia (SAID, 2007).

A realidade empírica, ao seu turno, demonstrou a marca do Século $X X$ com a precariedade e instabilidade dos sistemas democráticos (ALMEIDA, 2013) (ABREGÚ, 2008) (BIGOLIN NETO; RODRIGUEZ, 2016), com a persistência da discriminação, estigmatização, perseguição, genocídio e preconceitos. A demanda inevitável do cenário seria, então, a luta contra o autoritarismo-totalitarismo e suas projeções ditatoriais, assim como pela emancipação e superação das violências, arbitrariedades, violações de direitos e rupturas democráticas.

Desde relações psicológicas deterioradas (CANIATO, 2000) até à constituição de um modo próprio de se conduzir a vida pública (MANSILLA, 2016), a 


\section{Personalidade Acadêmica Homenageada:}

\section{Carlos Aurélio Mota de Souza (Universidade Ibirapuera - UNIB)}

presença constante do autoritarismo, do ódio à democracia (RANCIÉRE, 2014) e da desconfiança democrática (ROSANVALLON, 2007) entraram e entram constantemente em profundo conflito com a racionalidade jurídica supra-destacada.

Há o risco de o Direito, ademais, ser funcionalizado nestas políticas arbitrárias, o que, contudo, é um movimento contrário à historicidade. É neste conflito do Direito, que se opõe à banalidade do mal e cuja construção dogmática contemporânea se deu nesta tônica, diante do autoritarismo, das arbitrariedades, da irresponsabilidade e pedantismo institucionais, que se posiciona o problema desta proposta, o que se realiza em termos da afirmação da resistência anti-democrática desta feição alteritária de compreensão do Direito.

Quanto à metodologia, trata-se de pesquisa teórico-acadêmica e qualitativa, sendo em seus objetivos descritivo-explicativa e, nos procedimentos técnicos, bibliográfica, com base lógica em raciocínio dialético e especulativo. O campo de reflexão é a Filosofia do Direito.

Enquanto resultados e contribuições desta pesquisa, pontua-se: 1. A abertura reflexiva da Filosofia Contemporânea do Direito influencia a compreensão de todas as práticas jurídicas contemporâneas, permitindo-se cenários de valoração, contextos de crítica e momentos de parada no fluxo linguístico para se refletir sobre o conteúdo e a teleologia das decisões que se têm tomado na esfera política e jurídica, especialmente pelo confronto com o Direito Internacional dos Direitos Humanos e suas políticas Pós Horror da Segunda Guerra Mundial. 2. O retorno à banalidade do mal, tomado no seu sentido do horror e mau políticos, permite realizar tanto um importante passo de racionalidade jurídica de resistência quanto, efetivamente, um verdadeiro movimento de justificação moral que orienta a construção normativo-jurídica concreta propriamente dita, sobretudo, em sua dimensão ética contemporânea de interdito da infiltração daquelas intoleráveis práticas e costumes oligárquicos, autoritários, arbitrários, parciais e persecutórios, que marcam e ainda hoje marcam as mais profundas violações da democracia. 
Personalidade Acadêmica Homenageada:

Carlos Aurélio Mota de Souza (Universidade Ibirapuera - UNIB)

\section{REFERÊNCIAS}

ABREGÚ, Martín. Direitos Humanos para todos: da luta contra o autoritarismo à construção de uma democracia inclusiva - um olhar a partir da Região Andina e do Cone Sul. SUR, Revista Internacional de Direitos Humanos, São Paulo, v. 5, n. 8, p. 06-41, jun. 2008.

ALMEIDA, João Daniel Lima de. História do Brasil. Brasília: FUNAG, 2013.

ANDRADE, Marcelo. A banalidade do mal e as possibilidades da educação moral: contribuições arendtianas. Rev. Bras. Educ., Rio de Janeiro, v. 15, n. 43, p. 109125, abr. 2010.

ARENDT, Hannah. Eichmann em Jerusalém. Um relato sobre a banalidade do mal. Tradução de José Rubens Siqueira. 14.ed. São Paulo: Companhia das Letras, 1999.

ARENDT, Hannah. Origens do totalitarismo. Tradução de Roberto Raposo. São Paulo: Companhia das Letras, 1989.

BIGOLIN NETO, Pedro; RODRIGUEZ, José Rodrigo. "Quando o fascismo se tornava cada vez mais forte": Direito e emancipação em Franz Neumann e Boaventura de Sousa Santos. Teoria Jurídica Contemporânea, Rio de Janeiro, v. 1, n. 2, p. 63-96, 2016.

BILLIER, Jean-Cassien. História da filosofia do direito. Tradução de Maurício de Andrade. Barueri: Manole, 2005.

BOTERO, Adolfo Jerónimo; LEAL GRANOBLES, Yuliana. El mal radical y la banalidad del mal: las dos caras del horror de los regímenes totalitarios desde la perspectiva de Hannah Arendt. Univ. philos., Bogotá, v. 30, n. 60, p. 99-126, jun. 2013.

CANIATO, Angela Maria Pires. Da violência no ethos cultural autoritário da contemporaneidade e do sofrimento psicossocial. Revista de Psicologia Social e Institucional, Londrina, v. 2, n. 2, p. 197-215, 2000.

FARALLI, Carla. A filosofia contemporânea do direito. São Paulo: Martins Fontes, 2006.

HABERMAS, Jurgen. Direito e Democracia: entre facticidade e validade. 2. ed. Tradução de Flávio Beno Siebeneichler. Rio de Janeiro: Tempo Brasileiro, 2003.

HABERMAS, Jurgen. Verdade e Justificação: ensaios filosóficos. São Paulo: Loyola, 2004. 
Personalidade Acadêmica Homenageada:

Carlos Aurélio Mota de Souza (Universidade Ibirapuera - UNIB)

LÉVINAS, Emmanuel. Entre nós: ensaios sobre a alteridade. 5. ed. Tradução de Pergentino S. Pivatto [Coord.].; Anisio Meinerz; Jussemar da Silva [et.al.]. Petrópolis: Vozes, 2010.

MANSILLA, Hugo Celso Felipe. El desamparo humano en medio de los procesos de modernización. Un breve ensayo de filosofía política en torno al totalitarismo con especial referencia al Tercer Mundo. Sig. Fil, México, v. 18, n. 35, p. 110-139, jun. 2016.

MORRISON, Wayne. Filosofia do direito. Dos gregos ao pós-modernismo. Tradução de Jefferson Luiz Camargo. São Paulo: Martins Fontes, 2006.

RANCIÉRE, Jacques. O ódio à democracia. Tradução de Mariana Echalar. São Paulo: Boitempo, 2014.

ROSANVALLON, Pierre. La contrademocracia. La política en la era de la desconfianza. Buenos Aires: Manantial, 2007.

SAID, Edward Wadie. Humanismo e crítica democrática. São Paulo: Companhia das Letras, 2007.

TRINDADE, Antônio Augusto Cançado. A humanização do direito internacional. Belo Horizonte: Del Rey, 2006. 